\title{
Estrategias para disminuir infecciones en terapia intensiva pediátrica polivalente
}

\author{
Strategies to reduce infections in pediatric intensive care unit
}

\author{
Yanina Vanesa Fortini \\ Médica Pediatra especialista en Cuidados Intensivos Pediátricos. Universidad de Buenos Aires. Argentina.
}

RESUMEN

Introducción: Se define como infección asociada al cuidado de la salud a aquella adquirida durante la internación hospitalaria y que no estuviese presente o en incubación al momento de la admisión del paciente. Constituyen un importante problema de salud pública y un indicador de la calidad de los servicios. Objetivos: Implementar estrategias de gestión para la prevención de las infecciones nosocomiales. Material y métodos: Estudio cuasiexperimental, de intervención con análisis de series temporales antes y después de la implementación del programa. Se propone el monitoreo de la higiene de manos y la aplicación de medidas de control para prevenir las bacteriemias asociadas con catéter venoso central (CVC), neumonías asociadas con la ventilación mecánica (NAV) e infecciones urinarias asociadas con sonda vesical (SV), en niños internados en una terapia intensiva pediátrica polivalente de un hospital público de Buenos Aires. Resultados: Se logró disminuir la tasa de utilización de los dispositivos, evitando prolongar su uso innecesario. La tasa más baja de bacteriemias relacionada con CVC se registró en 2018, y durante el año 2019 se mantuvo en 4.02. La tasa de NAV descendió luego de la intervención. En los últimos tres años no se reportaron infecciones urinarias asociadas con SV. El $81 \%$ de los profesionales logró adherencia a la higiene de manos. Conclusiones: La educación del personal, la adherencia a las buenas prácticas y la vigilancia epidemiológica fueron los ejes centrales. La implementación de las diferentes estrategias permitió evaluar el impacto final de las medidas preventivas y promovió el trabajo en equipo.

Palabras clave: Prevención de infecciones asociadas al cuidado de la salud, Unidad de Cuidados Intensivos Pediátricos, estrategias de gestión.

\section{INTRODUCCIÓN}

Las infecciones asociadas al cuidado de la salud (IACS) son definidas como toda infección localizada

Citar como: Fortini YV. Estrategias para disminuir infecciones en terapia intensiva pediátrica polivalente. Rev Latin Infect Pediatr. 2021; 34 (2): 82-93. https:// dx.doi.org/10.35366/100547

Recibido: 29-12-2020. Aceptado: 01-03-2021.

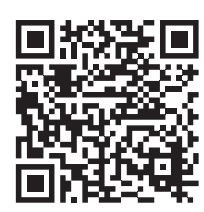

ABSTRACT

Introduction: Infections associated with health care are defined as those acquired during hospitalization and that were not present, or in incubation, at the time of the patient's admission. They constitute an important public health problem and an indicator of the quality of services. Objectives: To implement management strategies for the prevention of nosocomial infections. Material and methods: A quasi-experimental, intervention study with time series analyses before and after program implementation. The monitoring of hand hygiene and the application of control measures are proposed to prevent central line-associated bloodstream infections (CLABSI), ventilator-associated pneumonias (VAP), or urinary catheter-associated urinary tract infections (CAUTI), in children hospitalized in a multipurpose pediatric intensive care of a public hospital in Buenos Aires. Results: It was possible to reduce the utilization rate of the devices, avoiding prolonging their unnecessary use. The lowest rate of CLABSI was recorded in 2018, and during the year 2019 it remained at 4.02. The VAP rate decreased after the intervention. In the last three years no CAUTI was reported. $81 \%$ of professionals achieved adherence to hand hygiene. Conclusions: Staff education, adherence to good practices and epidemiological surveillance were the central axes. The implementation of the different strategies allowed to evaluate the final impact of preventive measures and promoted teamwork.

Keywords: Prevention of health care associated infections, pediatric intensive care unit, management strategies.

o sistémica producida a consecuencia de una reacción adversa a la presencia de uno o más agentes infecciosos o sus toxinas, que se presenta en un paciente asistido en una institución de salud y que no estuviese presente o incubándose al momento de la admisión del caso, excepto que la infección se relacione con una admisión previa en la misma institución. ${ }^{1,2}$ Representan una problemática que abarca a todo el ámbito de la salud, no sólo por la cantidad de pacientes afectados, sino también por la presencia

www.medigraphic.com/infectologiapediatrica 
Rev Latin Infect Pediatr. 2021; 34 (2): 82-93

de gérmenes multirresistentes que obligan a emplear tratamientos antibióticos de amplio espectro.

Las infecciones asociadas con los procedimientos invasivos son las complicaciones más importantes derivadas de su uso en los pacientes internados en las unidades de cuidados intensivos pediátricos (UCIP). Estos casos presentan riesgos asociados con su enfermedad de base y gravedad, sumados a los riesgos de su tratamiento, requiriendo el uso de procedimientos invasivos y periodos de internación prolongados, lo cual los expone a sufrir nuevos episodios de infecciones hospitalarias. La prevención de las infecciones nosocomiales es un componente esencial de las distintas iniciativas implementadas para mejorar la seguridad de los pacientes hospitalizados. ${ }^{3}$ Se calcula que un $15 \%$ de los hospitalizados desarrollan una IACS durante su estancia hospitalaria. En Estados Unidos este dato implica que ocurren aproximadamente 1.7 millones de IACS por año y 99,000 muertes atribuibles a estos eventos adversos. ${ }^{4}$ El estudio IBEAS (Iberoamerican Study of Adverse Events) informó que las infecciones nosocomiales constituyen el principal evento adverso identificado. ${ }^{5}$ Las tres infecciones intrahospitalarias más frecuentes descriptas en niños internados en UCIP son las bacteriemias asociadas con catéter venoso central (CVC), neumonías asociadas con la ventilación mecánica (NAV) y las infecciones del tracto urinario (ITU) asociadas con sonda vesical (SV). MorilloGarcía y colaboradores describen que en una UCIP de España, el costo mediano de la estadía de pacientes con IACS fue casi ocho veces mayor que el costo mediano de los pacientes sin infección. Estos costos estuvieron asociados con una mayor utilización de antibióticos endovenosos, nutrición enteral-parenteral y estudios diagnósticos por imágenes y prolongación de los días de internación, con una diferencia de 21 días entre los pacientes con y sin infección nosocomial. ${ }^{6}$

Las prácticas dirigidas a controlar las infecciones intrahospitalarias son un factor clave para reducir su transmisión horizontal dentro del hospital. Las IACS constituyen un problema de gran importancia clínica y epidemiológica, debido a que condicionan el incremento en las tasas de morbilidad y mortalidad, por ello su vigilancia epidemiológica se inscribe dentro de los propósitos de un programa de control de infecciones para garantizar la calidad de la atención médica, al permitir la aplicación de normas, procedimientos, criterios y sistemas de trabajo multidisciplinario para la identificación temprana, el estudio, el control y la prevención de las IACS.

Los criterios para el diagnóstico de las infecciones intrahospitalarias son los utilizados por el Programa Nacional de Vigilancia de Infecciones Hospitalarias de Argentina (VIHDA), comparables con los publicados por el National Healthcare Safety Network (NHSN) del Center for Disease Control and Prevention (CDC) en Estados Unidos. En Argentina se desarrolla el Programa Nacional de Epidemiología y control de infecciones hospitalarias llamado VIHDA bajo la responsabilidad del Instituto Nacional de Epidemiología «Dr. Juan H. Jara». Este instituto forma parte de la Administración Nacional de Laboratorios e Institutos de Salud «Dr. Carlos Malbrán», que es un organismo dependiente del Ministerio de Salud de la Nación y se encarga de publicar las estadísticas nacionales de las infecciones.

El objetivo general de esta investigación es implementar estrategias de gestión para la disminución de IACS en una UCIP polivalente de un hospital público municipal. Los objetivos específicos son: describir las estrategias multimodales para mejorar la adherencia del personal de salud a la higiene de manos, y los combos específicos para disminuir las bacteriemias asociadas con CVC, NAV e ITU asociada con SV. Alcanzar una adherencia a la higiene de manos del $80 \%$ en el plazo de un año. Disminuir la tasa de bacteriemias asociadas con CVC en un $50 \%$ en el plazo de un año. Disminuir la tasa de NAV en un $50 \%$ en el plazo de un año. Mantener en cero la tasa de ITU asociada con SV (tasa por mil días de uso).

El concepto de paquetes de medidas fue desarrollado por el Institute of Health Care Improvement, y propone que cuando estos elementos o medidas se ejecuten en forma conjunta producirán un resultado mejor que si se los lleva a cabo de forma individual. Cada medida es introducida basada en el grado de evidencia existente. ${ }^{7}$

La justificación para implementar esta investigación se respalda en que los pacientes internados en la UCIP tienen mayor riesgo de adquirir IACS porque están expuestos a más procedimientos invasivos y generalmente sus enfermedades de base son más severas.

\section{MATERIAL Y MÉTODOS}

Se evaluó el impacto sobre la incidencia de infecciones intrahospitalarias antes y después de la 
implementación del paquete de medidas tendientes a prevenirlas.

Diseño: estudio cuasiexperimental (antesdespués) de intervención con análisis de series temporales (prospectivo), de la implementación de un programa de estrategias de gestión para la disminución de la incidencia de las infecciones intrahospitalarias en la UCIP del Hospital Abete. A través de este diseño, se podrá observar si la aplicación de todas las estrategias implementadas en forma simultánea fue beneficiosa, comparándose con los registros de las planillas de infecciones previas al comienzo del programa. Considerando que se trata de un trabajo con impacto en el sistema de salud, no se realizó con grupo control. Se asume que las diferencias observadas en los resultados se deben a la intervención.

Población y muestra: niños del Partido de Malvinas Argentinas y/o con obra social internados en la UCIP del Hospital de Trauma y Emergencias «Dr. Federico Abete». Muestra no aleatoria consecutiva.

Universo o población objetivo: niños con CVC, SV y/o en asistencia respiratoria mecánica (ARM) internados en la UCIP.

Criterios de inclusión: pacientes pediátricos mayores de un mes de vida y menores de 16 años internados en la UCIP. Pacientes que requieran ARM, CVC y/o SV.

Criterios de exclusión: pacientes menores de un mes de vida o mayores de 16 años. Pacientes con evidencia clínica, radiológica o microbiológica de neumonía dentro de las 48 horas del inicio de ARM. Pacientes sin ARM, sin CVC y/o sin SV.

Selección y tamaño de la muestra: las intervenciones del proyecto están dirigidas a todos los niños entre los 30 días de vida y los 16 años, que se encuentran internados en la UCIP polivalente del Hospital de Trauma y Emergencias «Dr. Federico Abete», desde el 1 de enero de 2019 al 31 de diciembre de 2019. Se registraron todas las infecciones intrahospitalarias asociadas con CVC, ARM y SV en dichos pacientes.

Variables: las variables dependientes que se registraron son la tasa de bacteriemias asociadas con CVC por mil días de CVC, tasa de NAV por mil días de ARM, tasa de ITU asociadas con SV por mil días de SV, tasa de utilización de CVC, tasa de utilización de ARM, tasa de utilización de SV y adherencia del personal de salud a la higiene de manos.

El uso de definiciones estandarizadas para la identificación de las IACS es importante en el proceso de vigilancia al permitir la correcta categorización de los eventos como verdaderas infecciones. Los criterios para el diagnóstico de las infecciones intrahospitalarias son los utilizados por el Programa Nacional VIHDA, comparables con los publicados por NHSN del CDC en Estados Unidos.

Los datos recolectados fueron ingresados a una planilla Excel y luego procesados. La fase I comprendió el control histórico (datos de IACS durante el periodo comprendido entre el 01 de enero de 2014 y el 31 de diciembre de 2018), la fase II el diseño y aplicación de la intervención (periodo de enero a diciembre de 2019) y la fase III el periodo postintervención (datos de IACS en periodo comprendido entre el 01 de enero y el 31 de diciembre de 2019).

No se consideró la necesidad de consentimiento informado dado que los registros e intervenciones forman parte de las prácticas usuales de la UCIP, y se tomaron los datos que registró la Unidad de Vigilancia Epidemiológica (UVE). La UVE está integrada por la enfermera en control de infecciones, el infectólogo pediátrico, el supervisor y los referentes de enfermería de cada turno y la jefa de servicio de la UCIP. Estos integrantes capacitaron a todo el equipo de salud (enfermeros, médicos, kinesiólogos) sobre la técnica correcta y los cinco momentos para la higiene de las manos, la difusión de las normas de procedimientos para la colocación de CVC y el paquete de medidas de prevención de NAV e ITU asociada con SV. La capacitación se realizó en clases presenciales, en cada uno de los turnos de trabajo durante la semana y los fines de semana. Debido a que nuestra institución es un hospital escuela, la UCIP recibe a médicos residentes rotantes, alumnos de la escuela de enfermería y residentes de kinesiología, por ello se realizaron mensualmente los talleres dirigidos a quienes iniciaban su rotación en la UCIP acerca de la higiene de manos y la prevención de las IACS.

A continuación se detalla la implementación del plan de mejora:

Planilla de observación de higiene de manos: se realizó una observación por turno de trabajo (de lunes a viernes se divide en tres turnos: de 07:00 a 14:00 h, de 14:00 a 21:00 h y de 21:00 a 07:00 $\mathrm{h}$; sábados, domingos y feriados se dividen en dos turnos: de 07:00 a 21:00 y de 21:00 a 07:00 h) por parte del personal seleccionado de la UVE (observador). El observador informa al personal 
Rev Latin Infect Pediatr. 2021; 34 (2): 82-93

seleccionado que será seguido durante una sesión de trabajo con los pacientes a su cargo. Finalizado el seguimiento, el observador se reúne con el observado para un análisis personalizado de los errores o aciertos detectados. Se realizaron sesiones de observación a todo tipo de personal: plantel estable (médicos, enfermeros y kinesiólogos), médicos interconsultores (cirujanos, ecografistas), asistentes de otras disciplinas (técnicos radiólogos, de hemoterapia, nutricionistas) que concurren a brindar servicios de atención directa a los pacientes internados en la UCIP. En la planilla de observación de higiene de manos, el observador marca con una cruz las oportunidades para realizar la higiene de manos, correspondientes a alguno de los cinco momentos establecidos. Si la acción se realiza, coloca una cruz en el casillero «lavado» o «frotado», según corresponda. Si esa oportunidad observada no se traduce en una acción efectiva, coloca una cruz en el casillero «no realizado» (Anexo 1). Cada unidad de paciente dispone de un frasco de solución de base alcohólica (alcohol gel) a fin de alentar la práctica de la higiene de manos. La farmacia del hospital realiza la provisión de dicho insumo a pedido de la UCIP.

Lista de chequeo para la inserción de CVC: el uso de esta lista de cotejo es necesaria para asegurar la adherencia a las prácticas de control de infecciones, cada vez que sea necesario colocar un CVC. Estas listas son completadas por algún integrante de la UVE, entrenado en la técnica correcta de colocación del CVC y con autoridad para suspender el procedimiento si uno de los pasos no se cumple. En principio la higiene de manos antes de la inserción del CVC, utilizando alcohol en gel o jabón antiséptico y agua. El uso de guantes no elimina la necesidad del lavado de manos previo. El kit prearmado con todos los elementos necesarios para la colocación del CVC fácilmente disponibles, el uso de antisépticos a base de clorhexidina al $2 \%$ para la preparación de la piel previo a la colocación del CVC permitiendo su secado antes de realizar la punción, y la utilización de máximas precauciones (camisolín, gorro, barbijo y guantes estériles) de barrera durante la inserción del CVC (Anexo 2). La solución de clorhexidina al $2 \%$ es provista por la farmacia hospitalaria, a pedido de la UCIP.

Se confeccionó un kit de colocación de CVC que contiene una compresa grande fenestrada, dos camisolines estériles, dos jeringas de $10 \mathrm{~mL}$, dos jeringas de $5 \mathrm{~mL}$, dos ampollas de solución fisio- lógica, dos agujas, hilo, tres llaves de tres vías, un tapón conector, un apósito transparente. Este kit es preparado por la farmacia del hospital y entregado a requerimiento de la UCIP. El médico que colocará el acceso venoso y su ayudante previo al procedimiento se colocarán gorro y barbijo, buscarán su paquete de guantes estériles adecuados y el CVC específico para el paciente.

Antes de la manipulación del CVC ya colocado, debe realizarse la higiene de manos, desinfectar las conexiones y los conectores antes de acceder al CVC, con el objetivo de reducir el nivel de colonización de estos dispositivos. La desinfección debe realizarse con alcohol $70 \%$ o clorhexidina alcohólica aplicando fricción durante 5 segundos. El cambio de las curaciones transparentes y cuidado del sitio de inserción con solución antiséptica basada en clorhexidina debe realizarse cada cinco a siete días o inmediatamente si la curación está manchada, húmeda o desplazada. Se deberán reemplazar los sets de administración cada 96 horas, excepto si fueron utilizados para la infusión de sangre, hemoderivados o lípidos.

Paquete de medidas de prevención de NAV: no existe consenso con relación a los paquetes de medidas indicados en pediatría para prevenir la NAV. Esta planilla fue completada por los médicos de guardia, una vez por día durante el pase de sala en todos los pacientes conectados a ARM (Anexo 3). Se propusieron como medidas de prevención la elevación de la cabecera de la cama entre 30-45 grados, la evaluación diaria de los niveles de sedoanalgesia y la realización de la prueba de desconexión a fin de acortar los periodos de ARM, a través de protocolos elaborados en la unidad. Otra estrategia es la prevención de las úlceras de estrés mediante el uso de omeprazol o sucralfato. El uso de tubos endotraqueales con balón manteniendo la adecuada insuflación del balón con una presión de 20 a $25 \mathrm{cmH}_{2} \mathrm{O}$. La higiene bucal con clorhexidina $0.12 \%$ es eficaz en la disminución de la incidencia de NAV, como también evitar traslados innecesarios y volúmenes gástricos excesivos a fin de impedir la aspiración de secreciones contaminadas. Al lado de cada una de estas estrategias, el médico de guardia marca con una cruz si la medida se realiza o no, en cada paciente.

Paquete de medidas de prevención de ITU asociada con SV: esta planilla fue completada en forma diaria, por el médico de guardia, una vez por día durante el pase de sala en todos los pacientes 
Rev Latin Infect Pediatr. 2021; 34 (2): 82-93

que contengan SV (Anexo 4). Se propusieron como medidas de prevención la colocación de SV con técnica aséptica, el lavado de manos antes y después de manipular cualquier parte del sistema urinario, mantener un sistema de drenaje continuo y cerrado, usar guantes no estériles para el contacto con la orina, y practicar la higiene perineal con soluciones antisépticas. Al lado de cada una de estas estrategias, el médico de guardia marca con una cruz si la medida se realiza o no en cada paciente.

El kit de colocación de SV contiene dos apósitos y cuatro gasas, un gel de xilocaína estéril, dos jeringas de $10 \mathrm{~mL}$, dos ampollas de agua destilada, un apósito transparente, una bolsa colectora, una compresa fenestrada estéril. El enfermero que colocará la SV deberá buscar la sonda adecuada para el paciente y el paquete de guantes estériles que utilizará en el procedimiento. Este kit es preparado por la farmacia del hospital y entregado a requerimiento de la UCIP.

Lista de chequeo en indicaciones médicas sobre necesidad de continuar con ARM, CVC y SV: los médicos de guardia marcan en la indicación médica preimpresa de cada paciente durante el pase de sala diario, si es necesaria la asistencia ventilatoria mecánica (Sí-No), el requerimiento de CVC (Sí-No) y el requerimiento de SV (Sí-No) (Anexo 5).

Los datos fueron sometidos a comparación interna y externa. Respecto a la primera de ellas, se pretende monitorear la evolución temporal de los indicadores, teniendo en cuenta que no se ha modificado la metodología de registro de IACS y tampoco han variado las características de la UCIP a lo largo del tiempo. Por otro lado, se realizó la comparación de nuestros datos con indicadores externos del programa nacional VIHDA y del NHSN de Estados Unidos.

Tabla 1: Observaciones de higiene de manos realizadas en la UCIP del Hospital Abete durante 2019.

\begin{tabular}{|c|c|c|c|c|c|c|}
\hline \multirow{2}{*}{$\begin{array}{c}\text { Año } 2019 \\
\text { Turnos }\end{array}$} & \multicolumn{3}{|c|}{245 días de semana } & \multicolumn{2}{|c|}{120 días de fin de semana } & \multirow[b]{2}{*}{ Total } \\
\hline & Mañana & Tarde & Noche & Diurno & Nocturno & \\
\hline Observaciones realizadas & 245 & 245 & 245 & 120 & 120 & 975 \\
\hline Observaciones que adhieren & 197 & 205 & 203 & 98 & 96 & 799 \\
\hline Observaciones que no adhieren & 48 & 40 & 42 & 22 & 24 & 176 \\
\hline Adherencia, \% & 80.41 & 83.67 & 82.85 & 81.66 & 80.00 & 81.94 \\
\hline
\end{tabular}

Tabla 2: Adherencia a la higiene de manos de los diferentes profesionales de la salud de la UCIP del Hospital Abete durante 2019.

\begin{tabular}{lcc} 
& \multicolumn{3}{c}{ Número de observaciones } \\
\cline { 2 - 3 } Profesionales & $\begin{array}{c}\text { Adhieren en forma } \\
\text { correcta a la higiene de } \\
\text { manos n (\%) }\end{array}$ & $\begin{array}{c}\text { No adhieren en forma } \\
\text { correcta a la higiene de } \\
\text { manos n (\%) }\end{array}$ \\
\hline Médicos & $349(43.68)$ & $87(49.43)$ \\
Enfermeros & $287(35.92)$ & $25(14.2)$ \\
Kinesiólogos & $105(13.14)$ & $39(22.17)$ \\
Asistentes de & $58(7.26)$ & $25(14.2)$ \\
otras disciplinas & $799(100)$ & $176(100)$ \\
Total & & \\
\hline UCIP = unidad de cuidados intensivos pediátricos.
\end{tabular}

\begin{tabular}{lc}
\multicolumn{2}{c}{$\begin{array}{c}\text { Tabla 3: Porcentaje de cumplimiento } \\
\text { en los diferentes momentos } \\
\text { de la higiene de manos. }\end{array}$} \\
\multicolumn{1}{c}{ Momentos de la higiene de manos } & $\begin{array}{c}\% \text { de } \\
\text { adherencia }\end{array}$ \\
\hline 1: Antes del contacto con el paciente & 85.0 \\
2: Antes de realizar tarea aséptica & 79.0 \\
3: Después del contacto con fluidos corporales & 82.0 \\
4: Después del contacto con el paciente & 84.0 \\
5: Después del contacto con el entorno & 72.0 \\
\hline UCIP = unidad de cuidados intensivos pediátricos. &
\end{tabular}


Rev Latin Infect Pediatr. 2021; 34 (2): 82-93

Tabla 4: Comparación de tasas anuales de utilización y bacteriemias asociadas con

CVC en el periodo pre- y postintervención en la UCIP del Hospital Abete.

\begin{tabular}{|c|c|c|c|c|c|c|c|}
\hline & & & & interven & & & Postintervención \\
\hline Bacteriemias as & ciadas a CVC & 2014 & 2015 & 2016 & 2017 & 2018 & 2019 \\
\hline $\begin{array}{l}\text { Número de } b \\
\text { asociada }\end{array}$ & $\begin{array}{l}\text { acteriemias } \\
\text { a CVC }\end{array}$ & 8 & 5 & 7 & 4 & 10 & 3 \\
\hline Pacient & s-día & 2,500 & 2,380 & 2,638 & 2,123 & 4,999 & 2,447 \\
\hline Días us & CVC & 910 & 843 & 1,155 & 583 & 2,822 & 746 \\
\hline & Hospital Abete & 0.36 & 0.35 & 0.43 & 0.27 & 0.56 & 0.30 \\
\hline utilización de CVC & NHSN* & 0.46 & 0.46 & 0.45 & 0.45 & 0.45 & NP \\
\hline & VIHDA** & 0.51 & 0.53 & 0.53 & 0.54 & 0.55 & NP \\
\hline Tasa anual & Hospital Abete & 8.79 & 5.93 & 6.06 & 6.86 & 3.54 & 4.02 \\
\hline bacteriemias por mil & NHSN* & 1.4 & 1.4 & 1.2 & 1.2 & 1.2 & NP \\
\hline días de uso CVC & VIHDA** & 4.1 & 4.59 & 4.1 & 4.6 & 3.3 & NP \\
\hline $\begin{array}{l}\text { CVC = catéter venos } \\
\text { Vigilancia de Infeccio } \\
\text { * Dudeck MA, Edwa } \\
\text { Control. 2015; } 43 \text { (3): } \\
\text { ** VIHDA (Programe } \\
\text { Laboratorios e Institu }\end{array}$ & $\begin{array}{l}\text { central; UCIP = un } \\
\text { es Hospitalarias de } \\
\text { Is JR, Allen-Bridso } \\
\text { O06-221. } \\
\text { Vigilancia Infeccior } \\
\text { s de Salud. Ministe }\end{array}$ & $\begin{array}{l}\text { cuidado } \\
\text { tina; NP } \\
\text { al. Nation } \\
\text { spitalaria } \\
\text { Salud de }\end{array}$ & $\begin{array}{l}\text { s pediátı } \\
\text { ado al m } \\
\text { are Safe } \\
\text { ntina). R }\end{array}$ & $\begin{array}{l}\mathrm{N}=\text { Nat } \\
\text { la prese } \\
\text { k report, } \\
\text { nuales. I }\end{array}$ & $\begin{array}{l}\text { hcare Sa } \\
\text { este tra } \\
\text { mary for } \\
\text { acional d }\end{array}$ & $\begin{array}{l}\text { ork, VIHD } \\
\text { jice-asso } \\
\text { iología. A }\end{array}$ & $\begin{array}{l}\text { ograma Nacional de } \\
\text { Module. Am J Infect } \\
\text { tración Nacional de }\end{array}$ \\
\hline
\end{tabular}

La UVE realizó la vigilancia de IACS en forma mensual y se recabaron los siguientes datos:

Total pacientes-día: número total de pacientes diarios en un mes.

Episodios de bacteriemias asociadas a CVC: número total de bacteriemias asociadas con CVC en un mes.

Total de días de uso CVC: días totales de uso de CVC en un mes.

Tasa bacteriemia por 1,000 días de uso CVC (\%): (número de bacteriemias asociadas con CVC en un mes/número de días de uso CVC en un mes) $\times 1,000$

Tasa de utilización de CVC: días de uso CVC en un mes/total pacientes-día mensuales.

Episodios de NAV: número total de NAV en un mes.

Total de días de uso de ARM: días totales de uso de ARM en un mes.

Tasa de NAV por 1,000 días de uso ARM (\%): (número de NAV en un mes/número de días de uso ARM en un mes) $\times 1,000$.

Tasa de utilización de ARM: días de uso ARM en un mes/total pacientes-día mensuales.
Episodios de ITU asociada con SV: número total de ITU en un mes.

Total de días de uso de SV: días totales de uso de SV en un mes.

Tasa ITU por 1,000 días de uso SV (\%॰): (número ITU asociada a SV en un mes/número de días de uso de SV en un mes) $\times 1,000$.

Tabla 5: Microorganismos prevalentes de

bacteriemias asociadas con CVC durante el periodo 2014-2019 en la UCIP del Hospital Abete.

201420152016201720182019 Total

$\begin{array}{lccccccc}\text { Pseudomona } & 4 & 2 & 3 & 1 & 5 & 1 & 16 \\ \text { Klebsiella } & 3 & 2 & 2 & 1 & 2 & 1 & 11 \\ \text { SAMR } & 1 & 0 & 0 & 0 & 0 & 1 & 2 \\ \text { SAMS } & 0 & 0 & 0 & 0 & 1 & 0 & 1 \\ \text { Stenotrophomonas } & 0 & 1 & 2 & 2 & 2 & 0 & 7 \\ \text { Total } & 8 & 5 & 7 & 4 & 10 & 3 & 37\end{array}$

CVC = catéter venoso central; UCIP = unidad de cuidados intensivos pediátricos; SAMR = Staphylococcus aureus meticilino resistente; SAMS = Staphylococcus aureus meticilino sensible. 
Rev Latin Infect Pediatr. 2021; 34 (2): 82-93

Tabla 6: Comparación de tasas anuales de utilización y NAV en el periodo pre- y postintervención en la UCIP del Hospital Abete.

\begin{tabular}{|c|c|c|c|c|c|c|c|}
\hline & & \multicolumn{5}{|c|}{ Preintervención } & \multirow{2}{*}{$\frac{\text { Postintervención }}{2019}$} \\
\hline \multicolumn{2}{|c|}{ NAV } & 2014 & 2015 & 2016 & 2017 & 2018 & \\
\hline \multicolumn{2}{|c|}{ Número de NAV } & 6 & 4 & 6 & 5 & 12 & 2 \\
\hline \multicolumn{2}{|c|}{ Pacientes-día } & 2,500 & 2,380 & 2,638 & 2,123 & 4,999 & 2,447 \\
\hline \multicolumn{2}{|c|}{ Días uso ARM } & 1,382 & 1,401 & 1,646 & 851 & 3,298 & 828 \\
\hline \multirow{3}{*}{$\begin{array}{c}\text { Tasa anual } \\
\text { utilización de ARM }\end{array}$} & Hospital Abete & 0.55 & 0.58 & 0.62 & 0.4 & 0.65 & 0.33 \\
\hline & $\mathrm{NHSN}^{*}$ & 0.37 & 0.37 & 0.37 & 0.37 & 0.37 & NP \\
\hline & VIHDA** & 0.63 & 0.56 & 0.61 & 0.57 & 0.60 & $\mathrm{NP}$ \\
\hline $\begin{array}{c}\text { Tasa anual de NAV } \\
\text { por mil días de uso } \\
\text { de ARM }\end{array}$ & $\begin{array}{c}\text { Hospital Abete } \\
\text { NHSN }^{*} \\
\text { VIHDA }^{* *}\end{array}$ & $\begin{array}{c}4.34 \\
0.8 \\
6\end{array}$ & $\begin{array}{c}2.85 \\
0.8 \\
4.81\end{array}$ & $\begin{array}{c}3.64 \\
0.7 \\
4.3\end{array}$ & $\begin{array}{c}5.87 \\
0.7 \\
4.8\end{array}$ & $\begin{array}{c}3.63 \\
0.7 \\
3.46\end{array}$ & $\begin{array}{l}2.41 \\
\mathrm{NP} \\
\mathrm{NP}\end{array}$ \\
\hline \multicolumn{8}{|c|}{$\begin{array}{l}\text { NAV = ventilación mecánica; UCIP = unidad de cuidados intensivos pediátricos; ARM = asistencia respiratoria mecánica; NHSN = National Healthcare Safety } \\
\text { Network; VIHDA = Programa Nacional de Vigilancia de Infecciones Hospitalarias de Argentina; NP = no publicado al momento de la presentación de este trabajo. } \\
\text { * Dudeck MA, Edwards JR, Allen-Bridson K et al. National Healthcare Safety Network report, data summary for 2013, Device-associated Module. Am J Infect } \\
\text { Control. 2015; } 43 \text { (3): 206-221. } \\
\text { ** VIHDA (Programa Vigilancia Infecciones Hospitalarias de Argentina). Reportes anuales. Instituto Nacional de Epidemiología. Administración Nacional de } \\
\text { Laboratorios e Institutos de Salud. Ministerio de Salud de la Nación. }\end{array}$} \\
\hline
\end{tabular}

Tasa de utilización de SV: días de uso SV en un mes/total pacientes-día mensuales.

Se calculó el porcentaje de adherencia de higiene de manos con la siguiente fórmula: (número de acciones realizadas de higiene de manos/número de oportunidades para practicar la higiene de manos) $\times 100$.

Al finalizar el año, se calcularon las tasas anuales y se realizó la comparación con las tasas de IACS nacionales del programa VIHDA de Argentina y las del NHSN de Estados Unidos.

\section{RESULTADOS}

Para el análisis del programa se consignó como etapa preintervención al periodo comprendido entre el 1 de enero de 2014 y el 31 de diciembre de 2018. El periodo postintervención incluyó desde el 01 de enero de 2019 hasta el 31 de diciembre de 2019.

Se realizaron 975 observaciones de lavado de manos a diferentes profesionales de la salud: 436 médicos, 312 enfermeros, 144 kinesiólogos y 83 asistentes de otras disciplinas (radiólogos, nutricionistas, entre otros). El $81.94 \%$ de los profesionales de la salud tuvo cumplimiento satisfactorio durante el monitoreo de la higiene de manos. En la Tabla 1 se detallan las observaciones realizadas durante los diferentes días y turnos semanales, y el porcentaje de adherencia. En el Hospital Abete, como en Argentina, no hay datos previos sobre la tasa de adherencia a la higiene de manos.

En cuanto al análisis de las profesiones, se registró mayor adherencia en el grupo de médicos (43.68\%) y enfermeros (35.92\%) (Tabla 2).

De los cinco momentos de higiene de manos, el momento que más se incumplió fue la falta de lavado luego de tocar el entorno del paciente ( $72 \%$ ) y tuvo mayor adherencia el momento antes del contacto con el paciente (85\%) (Tabla 3).

Tabla 7: Microorganismos prevalentes de NAV durante el periodo 2014-2019 en la UCIP del Hospital Abete.

\begin{tabular}{lccccccc} 
& 2014 & 2015 & 2016 & 2017 & 2018 & 2019 & Total \\
\hline Pseudomona & 3 & 2 & 2 & 2 & 5 & 1 & 15 \\
Klebsiella & 2 & 1 & 1 & 2 & 3 & 1 & 10 \\
Acinetobacter & 1 & 0 & 2 & 0 & 1 & 0 & 4 \\
Influenza & 0 & 1 & 0 & 0 & 2 & 0 & 3 \\
Stenotrophomonas & 0 & 0 & 1 & 0 & 1 & 0 & 2 \\
Escherichia coli & 0 & 0 & 0 & 1 & 0 & 0 & 1 \\
Total & 6 & 4 & 6 & 5 & 12 & 2 & 35 \\
\hline
\end{tabular}

NAV = ventilación mecánica; UCIP = unidad de cuidados intensivos pediátricos . 
Rev Latin Infect Pediatr. 2021; 34 (2): 82-93

Tabla 8: Comparación de tasas anuales de utilización y las ITU asociadas con SV en el periodo pre- y postintervención en la UCIP del Hospital Abete.

\begin{tabular}{l}
$\begin{array}{l}\text { ITU asociada con sonda vesical } \\
\text { (ITU-SV) }\end{array}$ \\
\cline { 2 - 5 }
\end{tabular}

Se trabajó también sobre la aplicación de un protocolo de colocación de CVC. En este aspecto se puso énfasis en la técnica de colocación de CVC y los cinco momentos del lavado de manos. Se discutió diariamente en el pase de sala sobre la necesidad de continuar con CVC en cada caso, con el objetivo de no prolongar innecesariamente su uso. En la Tabla 4 se detallan los datos relevados en el periodo pre- y postintervención respecto al número total de episodios de bacteriemia, total pacientes-día, días uso CVC, tasa de utilización de CVC y tasa de bacteriemia relacionada con CVC expresada cada mil días de uso del dispositivo.

Las tasas anuales de bacteriemias relacionadas a CVC en el periodo preintervención variaron de 3.54 a 8.79 por cada mil días de uso del dispositivo. La tasa más baja se registró en 2018, y durante el periodo postintervención se mantuvo en 4.02. Este indicador comparado con los datos nacionales del programa VIHDA y del NHSN de Estados Unidos se mantiene en niveles aún elevados. Sólo durante el 2018 alcanzamos valores levemente superiores a los registros del programa VIHDA (Tabla 4). Las tasas anuales de utilización de CVC en la fase preintervención fue entre 0.27 y 0.56 , luego de la intervención la tasa registrada fue de 0.30 . Estos valores se mantuvieron por debajo del indicador del NHSN y del VIHDA, excepto en 2018 que obtuvimos valores más elevados en tasa de utilización de este dispositivo. Durante el periodo postintervención, la reducción en la tasa de utilización de CVC significó un mayor control en la permanencia innecesaria del dispositivo (Tabla 4).

Los patógenos más prevalentes en las bacteriemias asociadas con CVC en nuestro servicio durante los años 2014 y 2019 fueron Pseudomona 43.24\%

\begin{tabular}{|c|c|c|c|c|c|c|c|}
\hline & 2014 & 2015 & 2016 & 2017 & 2018 & 2019 & Total \\
\hline Pseudomona & 1 & 1 & 1 & 0 & 0 & 0 & 3 \\
\hline Klebsiella & 1 & 0 & 1 & 0 & 0 & 0 & 2 \\
\hline Candida & 0 & 1 & 0 & 0 & 0 & 0 & 1 \\
\hline Escherichia coli & 0 & 0 & 1 & 0 & 0 & 0 & 1 \\
\hline Total & 2 & 2 & 3 & 0 & 0 & 0 & 7 \\
\hline
\end{tabular}


$(n=16)$, Klebsiella $29.72 \%(n=11)$ y Stenotrophomonas $18.91 \%(n=7)$ (Tabla 5).

Otra de las medidas específicas consistió en instaurar un protocolo en prevención de NAV, centralizado en un paquete de medidas basadas en la mejor evidencia científica aplicadas en forma conjunta. Se discutió diariamente en el pase de sala sobre la indicación de continuar con ARM en cada paciente. En la Tabla 6 se detallan los datos relevados en el periodo pre- y postintervención respecto al número total de episodios de NAV, total pacientes-día, días uso ARM, tasa de utilización de ARM y tasa de NAV por cada mil días de uso del respirador.

Las tasas anuales de NAV en el periodo preintervención registraron valores entre 2.85 y 5.87 por cada mil días de uso de ARM. En el periodo postintervención, este indicador descendió a 2.41. Estos datos comparados con las tasas del NHSN y del programa VIHDA se mantuvieron aún elevados. La tasa anual de utilización de ARM ha variado entre 0.4 y 0.65 en el periodo preintervención. Luego de la aplicación de medidas de intervención, la tasa anual descendió a la mitad (0.33), lo que revela una mayor vigilancia de la necesidad de continuidad de la ventilación mecánica, y no prolongar innecesariamente su uso. Este último dato fue más bajo que el reportado por el NHSN y VIHDA durante el periodo 2014-2018 (Tabla 6). La aplicación de estas estrategias de intervención ha permitido descender las tasas de NAV por mil días de uso del dispositivo y la tasa de utilización de ARM en nuestra UCIP.

Los patógenos más prevalentes de NAV en nuestro servicio durante los años 2014 y 2019 fueron Pseudomona 42.85\% ( $n=15)$, Klebsiella 28.57\% ( $n$ $=10)$ y Acinetobacter $11.42 \%(n=4)$ (Tabla 7$)$.

Por último, se trabajó en la aplicación de un paquete de medidas de prevención de ITU asociada con SV. Se discutió diariamente en el pase de sala sobre la necesidad de mantener la SV en cada paciente. En la Tabla 8 se detallan los datos relevados en el periodo pre- y postintervención respecto al número total de episodios de ITU asociada con SV, total pacientes-día, días uso SV, tasa de utilización de SV y tasa de ITU relacionada con SV por cada mil días de uso del dispositivo. Las tasas anuales de ITU asociada con SV por mil días de uso del dispositivo en los últimos tres años fueron nulas, lo cual nos posiciona en mejor lugar respecto a las tasas del NHSN y del programa VIHDA. Ello está directamente relacionado con limitar los días de permanencia de SV y evitar la cateterización urinaria innecesaria. La tasa de utilización de SV en el periodo postintervención ha sido la más baja. Durante el periodo preintervención esta tasa varió entre 0.06 y 0.31 , con datos del NHSN de 0.21 y del programa VIHDA que rondaba 0.45 a 0.52 durante el periodo 2014-2018 (Tabla 8).

Los patógenos más prevalentes de ITU asociada con SV en nuestro servicio durante los años 2014 y 2019 fueron Pseudomona 42.85\% $(n=3)$ y Klebsiella $28.57 \%(\mathrm{n}=2)$ (Tabla 9).

\section{CONCLUSIONES}

La aplicación de estrategias destinadas a modificar prácticas y conductas en los profesionales de la salud, junto a los procesos de registros y monitoreo, han permitido optimizar los resultados en la prevención de las infecciones intrahospitalarias.

La prevención de las infecciones asociadas con cualquier dispositivo invasivo (ARM, CVC y SV) se basa en utilizarlos exclusivamente si hay indicación precisa, asegurando una técnica de inserción adecuada y su remoción en forma precoz. Asimismo se recomienda el control de la técnica de higiene de manos como complemento a la medición de la adherencia.

Todos los esfuerzos del programa estuvieron centrados en la educación del personal y su adherencia a las prácticas para mejorar el cumplimiento. La implementación de estas estrategias ha promovido la mejora del trabajo en equipo y de la calidad asistencial en la institución.

La reducción de las infecciones intrahospitalarias fue factible mediante la existencia de un programa activo en control de infecciones y campañas educativas para el cumplimiento de las medidas de prevención. Consideramos que los resultados obtenidos muestran evidencia suficiente para que el mismo continúe siendo implementado.

\section{REFERENCIAS}

1. Ivalo S. Programa de vigilancia y control de las infecciones asociadas a los cuidados de la salud. En: Rezzónico R, Menzica C, Rezzónico M. Auditoría médica y garantía de calidad de la gestión sanitaria. Buenos Aires: Ediciones Journal; 2016. pp. 690-715.

2. Cornistein W. Control de infecciones en cuidados intensivos. En: Gallesio A, Schnitzler E, Cosenza S, Arias López M. Gestión de áreas críticas. Buenos Aires: Editorial Panamericana; 2018. pp. 379-386. 
Rev Latin Infect Pediatr. 2021; 34 (2): 82-93

3. Shekelle PG, Pronovost PJ, Wachter RM, McDonald KM, Schoelles K, Dy SM et al. The top patient safety strategies that can be encouraged for adoption now. Ann Intern Med. 2013; 158 (5 Pt 2): 365-368.

4. Klevens RM, Edwards JR, Richards CL Jr, Horan TC, Gaynes RP, Pollock DA et al. Estimating health careassociated infections and deaths in U.S. hospitals, 2002. Public Health Rep. 2007; 122 (2): 160-166.

5. Aranaz-Andrés JM, Aibar-Remón C, Limón-Ramírez R, Amarilla A, Restrepo FR, Urroz O et al. Prevalence of adverse events in the hospitals of five Latin American countries: results of the 'Iberoamerican Study of Adverse Events' (IBEAS). BMJ Qual Saf. 2011; 20 (12): 10431051.

6. Morillo-García A, Aldana-Espinal JM, Olry de Labry-Lima A, Valencia-Martín R, López-Márquez R, Loscertales-Abril M et al. Hospital costs associated with nosocomial infections in a pediatric intensive care unit. Gac Sanit. 2015; 29 (4): 282287.

7. Gallesio A. Componentes generales de un proceso y proceso central de atención en la unidad de cuidados intensivos. En: Gallesio A, Schnitzler E, Cosenza S, Arias López M. Gestión de áreas críticas. Buenos Aires: Editorial Panamericana; 2018. pp. 145-160.

Financiamiento: Ninguno.

Conflicto de intereses: Ninguno.

Correspondencia:

Yanina Vanesa Fortini

E-mail: yaninafortini@yahoo.com.ar 


\section{Anexo 1: Planilla de observación diaria de higiene de manos.}

Observador:

Fecha: Indicaciones

Precontacto con el paciente

Pretarea aséptica

Postcontacto fluidos corporales

Postcontacto con el paciente

Postcontacto con el entorno
Profesión del observado:

Hora:

Modo

Frotado

Lavado

No realizado

\section{Anexo 2: Planilla de inserción de CVC.}

Paquete de medidas para la inserción de CVC

\section{Paciente:}

Historia clínica:

Fecha:

Operador:

Ayudante:

Higiene de manos

\begin{tabular}{|c|c|c|c|c|}
\hline \multirow[t]{2}{*}{ Operador } & M1 & Antes del contacto con el paciente & Sí & No \\
\hline & M2 & Antes de realizar una tarea aséptica (colocación CVC) & Sí & No \\
\hline Ayudante & M1 & Antes del contacto con el paciente & Sí & No \\
\hline \multicolumn{3}{|c|}{ Bandeja o kit con todos los elementos necesarios para la inserción del CVC } & Sí & No \\
\hline \multicolumn{3}{|c|}{ Antisepsia adecuada del sitio de inserción con clorhexidina solución al 2\% } & Sí & No \\
\hline \multicolumn{3}{|c|}{ Aplicación mediante frotado sobre la piel (30 segundos a 2 minutos) } & Sí & No \\
\hline \multicolumn{3}{|c|}{ Tiempo de espera (1-2 minutos) para secado del antiséptico antes de punzar la piel } & Sí & No \\
\hline \multicolumn{3}{|c|}{$\begin{array}{l}\text { Uso de barreras máximas de precaución para el paciente: cobertura completa con compresa } \\
\text { estéril grande }\end{array}$} & Sí & No \\
\hline \multicolumn{5}{|c|}{ Uso de barreras máximas de precaución } \\
\hline
\end{tabular}

\begin{tabular}{|c|c|c|c|c|c|c|}
\hline $\begin{array}{l}\text { Uso de camisolín estéril } \\
\text { (operador) }\end{array}$ & Sí & No & $\begin{array}{l}\text { Uso de camisolín estéril } \\
\text { (ayudante) }\end{array}$ & Sí & No & Comentarios: \\
\hline Uso de gorro (operador) & Sí & No & Uso de gorro (ayudante) & Sí & No & Comentarios: \\
\hline Uso de barbijo (operador) & Sí & No & Uso de barbijo (Ayudante) & Sí & No & Comentarios: \\
\hline $\begin{array}{l}\text { Uso de guantes estériles } \\
\text { (operador) }\end{array}$ & Sí & No & $\begin{array}{l}\text { Uso de guantes estériles } \\
\text { (ayudante) }\end{array}$ & Sí & No & Comentarios: \\
\hline
\end{tabular}

$\mathrm{CVC}=$ catéter venoso central. 
Rev Latin Infect Pediatr. 2021; 34 (2): 82-93

\section{Anexo 3: Medidas de prevención de NAV.}

Intervenciones para la prevención de neumonías asociadas con ventilación mecánica

\begin{tabular}{|c|c|c|}
\hline Estrategias para adhesión al lavado de manos y utilización de barreras de contacto & Sí & No \\
\hline Cabecera $30^{\circ}-45^{\circ}$ & Sí & No \\
\hline Tubos endotraqueales con balón & Sí & No \\
\hline Interrupción diaria de sedoanalgesia para evaluar extubación & Sí & No \\
\hline Evitar volúmenes gástricos excesivos (menos $1,500 \mathrm{~mL} / \mathrm{m}^{2}$ ) & Sí & No \\
\hline Evitar traslados innecesarios & Sí & No \\
\hline Prevención de úlcera de estrés (omeprazol, sucralfato) & Sí & No \\
\hline Higiene bucal con clorhexidina $0.12 \%$ & Sí & No \\
\hline
\end{tabular}

NAV = neumonías asociadas con ventilación mecánica.

\section{Anexo 4: Medidas de prevención de ITU asociadas con SV.}

Intervenciones para la prevención de ITU

asociadas con sonda vesical

Sonda vesical colocada con técnica aséptica

Lavado de manos antes y después de manipular cualquier parte del sistema urinario

Sí No

Usar guantes no estériles para el contacto con la orina

Si

No

Mantener un sistema de drenaje continuo y cerrado

Sí

No

Higiene perineal diaria con soluciones antisépticas

Sí

No

ITU = infecciones del tracto urinario; SV = sonda vesical.

Anexo 5: Indicaciones médicas diarias para cada paciente.

Planilla de indicaciones médicas UCIP

Fecha:

Apellido y nombre del paciente:

No DNI:

Diagnóstico:

Peso:

Superficie corporal:

\section{Asistencia respiratoria mecánica}

2. Requiere catéter venoso central

3. Requiere sonda vesical

$\begin{array}{ll}\text { Sí } \square & \text { No } \square \\ \text { Sí } \square & \text { No } \square \\ \text { Sí } \square & \text { No } \square\end{array}$

UCIP = unidad de cuidados intensivos pediátricos. 